\title{
CARACTERIZAÇÃO DO CONSUMO DE SUPLEMENTOS NUTRICIONAIS EM PRATICANTES DE ATIVIDADE FÍSICA EM ACADEMIAS
}

\author{
CARACTERIZATION OF NUTRITIONAL SUPPLEMENTS USE BY \\ PERSONS PRACTICING PHYSICAL EXERCISE AT GYMS
}

\author{
Gisele Sales Gomes ${ }^{1}$, Gabriel Carvalho Degiovanni², Monike Ribeiro Garlipp², \\ Paula Garcia Chiarello ${ }^{3}$, Alceu Afonso Jordão $\mathrm{Jr}^{3}$
}

\begin{abstract}
${ }^{1}$ Nutricionista e Mestre em Investigação Biomédica; ${ }^{2}$ Alunos do Curso de Nutrição e Metabolismo; ${ }^{3}$ Docentes do Curso de Nutrição e Metabolismo, Departamento de Clínica Médica. Faculdade de Medicina de Ribeirão Preto - USP.

Correspondência: Prof. Dr. Alceu Afonso Jordão Júnior. Departamento de Clínica Médica - Curso de Nutrição e Metabolismo. Faculdade de Medicina de Ribeirão Preto - USP. Av. Bandeirantes, 3900. 14049-900 Ribeirão Preto/SP. ～(alceu @fmrp.usp.br)
\end{abstract}

Gomes GS, Degiovanni GC, Garlipp MR, Chiarello PG, Jordão Jr AA. Caracterização do consumo de suplementos nutricionais em praticantes de atividade física em academias. Medicina (Ribeirão Preto) 2008; 41 (3): 327-31.

RESUMO: Introdução: A procura por suplementos nutricionais está tornando-se cada vez mais comum entre os freqüentadores de academias de ginástica, muitas vezes sem uma orientação adequada. Objetivo: O objetivo desse trabalho foi verificar o uso de suplementos nutricionais por praticantes de atividade física em academias de Ribeirão Preto-SP e seu impacto na composição corporal. Métodos: Para realização da pesquisa foram aplicados questionários em 102 indivíduos, do sexo masculino, com idades entre 20 e 40 anos, em 10 academias de ginástica de Ribeirão Preto-SP. Após o preenchimento do questionário, 30 indivíduos foram submetidos à avaliação da composição corporal e classificados em 3 grupos com 10 indivíduos: sem consumo de suplementos (GC), consumo exclusivo de suplementos protéicos (GP) e uso de suplementos protéico-energéticos (GPE). Resultados: Os resultados mostraram que $52 \%$ utilizam algum tipo de suplemento. A musculação era praticada por $92 \%$ dos entrevistados, sendo o aumento de massa magra, o principal objetivo relatado. A quantidade protéica consumida por meio dos suplementos significava, em média, $47 \%$ e $48 \%$ respectivamente para GP e GPE, da proteína que seria necessária por dia, considerando a recomendação de $1 \mathrm{~g}$ proteína por quilo de peso corporal. Enquanto o nutricionista é o profissional mais procurado para a orientação de dietas, o instrutor de musculação é o profissional mais requisitado pelos alunos para a utilização de suplementos. A avaliação da composição corporal mostrou percentual de massa magra e percentual de gordura corporal semelhantes entre os que faziam ou não uso de suplementos. Conclusão: O consumo de suplementos pelos freqüentadores de academias é elevado, muitas vezes sem uma orientação especializada e adequada, e pelos métodos utilizados não se verificou diferença na composição corporal com a utilização destes produtos.

Descritores: Composição Corporal. Atividade Física. Dieta. Exercício.

\section{1- INTRODUÇÃO}

A procura por suplementos nutricionais, especialmente pelos protéico-energéticos, está tornando- se cada vez mais comum entre os freqüentadores de academias de ginástica, principalmente motivados pelo desejo do ganho de massa muscular. Estes suplementos, além de serem utilizados com finalidade ergogênica, 
têm sido também utilizados para se melhorar a estética em ambientes de prática de exercícios físicos, como academias de ginástica e associações esportivas ${ }^{1}$. O uso indiscriminado destes suplementos é influenciado por instrutores, professores ou treinadores, atingindo $31 \%$ dos praticantes de exercícios físicos, não havendo, em muitos casos, a orientação por nutricionistas e/ou médicos esportistas ${ }^{1,2,3}$.

O uso de suplementos nutricionais está bastante difundido entre praticantes de atividade física e atletas, com o intuito de aumentar a performance em esportes de competição, no caso dos atletas, mas também em atividades recreacionais ${ }^{4,5}$.

Nos esportes de alta performance os suplementos nutricionais podem representar um risco, pois muitos destes suplementos contêm substâncias proibidas, como os esteróides anabólicos androgênios, o que poderia levar a um teste positivo de doping ${ }^{6,7}$.

Mesmo com a grande preocupação dos freqüentadores das academias na busca de uma alimentação ideal e adequada ao tipo de treino, ainda nos deparamos com a falta de conhecimentos, presença de hábitos alimentares inadequados e a influência da mídia, como fatores que levam os indivíduos a utilizarem suplementos nutricionais e adotarem um comportamento alimentar inadequado para atingirem determinados objetivos $^{8}$.

Diante do exposto o objetivo deste trabalho foi verificar o consumo de suplementos nutricionais entre os freqüentadores de academias e avaliar as possíveis alterações na composição corporal, o que poderia justificar a utilização destes suplementos.

\section{2- MÉTODOS}

Para avaliação do consumo de suplementos, participaram do estudo indivíduos saudáveis, do sexo masculino, com idades entre 20 e 40 anos, praticantes de atividade física em academias de Ribeirão Preto SP. Foram escolhidas aleatoriamente dez diferentes academias, onde foram entregues questionários sobre a utilização de suplementos para que fossem preenchidos voluntariamente pelos próprios alunos. Todos os alunos das academias tinham acesso e podiam preencher o questionário. Ao final de dois meses foram preenchidos um total de 102 questionários.

Antes do preenchimento do questionário, os participantes foram informados sobre a finalidade do estudo, e após seu aceite, assinaram um termo de consentimento, aprovado pelo Comitê de Ética em Pesquisa do Hospital das Clínicas de Ribeirão Preto-SP.
Após o preenchimento deste questionário, foram selecionados de modo aleatório 30 voluntários, de acordo com os seguintes critérios: nunca ter utilizado suplementos, ou estar consumindo algum tipo de suplemento há pelo menos dois meses. Nenhum participante relatou uso de anabolizantes. Posteriormente foram encaminhados à Unidade Metabólica do Hospital das Clínicas de Ribeirão Preto, para coleta de dados referentes à composição corporal, através de bioimpedância elétrica (BIA-RJL Systems) e somatório das pregas cutâneas, segundo técnicas padronizadas na Divisão de Nutrologia ${ }^{9,10}$. Após a coleta dos dados citados acima, os participantes foram separados de acordo com o uso de suplemento e o tipo consumido.

- Grupo controle (GC, N=10) - formado por aqueles que nunca ingeriam suplementos;

- Grupo protéico (GP, N=10) - formado por aqueles que ingeriram somente suplementos protéicos;

- Grupo protéico-energético (GPE, N=10) - formado por aqueles que além dos suplementos protéicos, consumiam suplementos energéticos.

A quantidade de proteína consumida por meio de suplementos foi calculada considerando as informações nutricionais dos rótulos e dosagem utilizada dos produtos.

Para a análise estatística dos dados referentes ao consumo de suplementos, utilizou-se o programa de informática Epi Info versão 3.2.2 (free-ware). Para os demais dados de composição corporal, foi utilizado o procedimento de Análise de Variância (ANOVA), para verificar a existência de possíveis diferenças entre as médias dos grupos. Foi considerado significativo $\mathrm{p}<0,05$.

\section{3- RESULTADOS}

\section{1- Consumo de Suplementos}

Foram respondidos 102 questionários deixados nas academias. Pelo cruzamento de dados de escolaridade com a utilização de suplementos, constatou-se que a maioria dos usuários $(\mathrm{n}=19 ; 35,8 \%)$, possuía o terceiro grau completo, $14(26,4 \%)$ o terceiro grau incompleto e $7(13,2 \%)$ eram pós-graduados. Todos os participantes analisados possuíam algum grau de instrução.

Quanto à utilização de suplementos, o estudo constatou que $52 \%(n=53)$ utilizavam algum tipo de 
suplemento, sendo que os mais consumidos foram BCAA (aminoácidos de cadeia ramificada), wheyprotein (proteína do soro do leite) e maltodextrina. Além destes, foram relatados o consumo de vitamina E e selênio (categoria de outros suplementos). A Figura 1 mostra o percentual dos tipos de suplementos consumidos. Entre os que não utilizam suplementos (48\%), 62,5\% relataram que já utilizaram e 37,5\% nunca o fizeram.

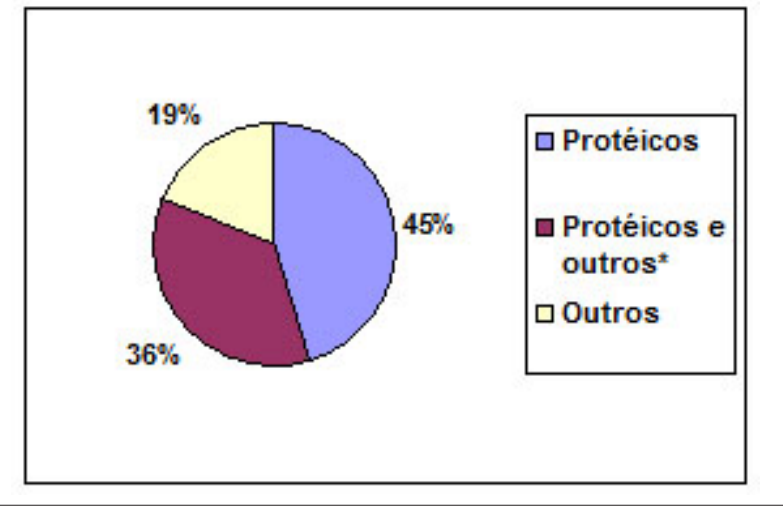

Figura 1 - Percentual dos tipos de suplementos consumidos pelos indivíduos.

*Energéticos e vitamínicos

Em relação à proteína adicional consumida por meio de suplementos, no GP este adicional ao consumo dietético foi em média de $36,5 \pm 33,9 \mathrm{~g} / \mathrm{dia}$, não muito diferente da proteína adicional no GPE $(36,9 \pm$ $37,3 \mathrm{~g} / \mathrm{dia}$ ). Estes valores de proteína significam $47,0 \%$ e 48,2\%, respectivamente para GP e GPE, da quantidade protéica que seria necessária no dia, considerando a recomendação de $1,0 \mathrm{~g}$ de proteína por quilo de peso corporal (Tabela I).

Tabela I: Médias ( \pm DP) e valores mínimos e máximos de consumo de proteínas por meio do uso de suplementos nutricionais.

GP GPE

\begin{tabular}{lll}
\hline Proteínas g/dia & $36,5 \pm 33,9$ & $36,9 \pm 37,3$ \\
Proteínas g/ Kg peso & $0,46 \pm 0,42$ & $0,49 \pm 0,51$ \\
Mín - máx & $0,02-1,17$ & $0,01-1,15$ \\
\hline
\end{tabular}

GP = Grupo Protéico.

GPE = Grupo Protéico-Energético.
A maioria dos entrevistados praticava a modalidade de musculação $(92,1 \%)$, com uma frequência superior a três vezes por semana, com o objetivo de aumento de massa magra $(73,53 \%)$, aumento de força $(26,5 \%)$, aumento da disposição $(24,5 \%)$ e emagrecimento $(22,5 \%)$.

Quanto às instruções do rótulo, 26 indivíduos (51\%), relatavam que seguiam as instruções indicadas.

Em relação à dieta, a maior parte dos indivíduos $(65,3 \%)$ já havia recebido alguma orientação, e dentre estes, o nutricionista encontrava-se em primeiro lugar $(29,7 \%)$, seguido do instrutor da academia $(20,8 \%)$ e médico $(18,8 \%)$. Em relação ao uso de suplementos, o educador físico é o profissional mais procurado pelos alunos $(33,7 \%)$, seguido do nutricionista e amigos $(15,8 \%)$ e, posteriormente, pelo médico $(7,9 \%)$.

\section{2- Avaliação da Composição Corporal}

A avaliação da composição corporal pelo IMC mostrou um índice de sobrepeso em 30\% dos indivíduos do grupo controle, comparado a $10 \%$ nos demais grupos. A obesidade Grau I foi encontrada em 10\% dos indivíduos, tanto no grupo controle como no grupo protéico. Apesar dos resultados de IMC serem elevados em alguns indivíduos, não houve diferença significativa entre as médias dos grupos.

O percentual de gordura corporal obtido por meio do somatório das pregas cutâneas foi menor que o resultado encontrado pela bioimpedância elétrica nos três grupos, entretanto, apesar desta discrepância, houve concordância entre os resultados obtidos pelos métodos (Coeficiente de Lin-0,65; IC-95\%).

Os valores médios e desvios-padrão do percentual de massa magra e gordura corporal, avaliados pelos métodos citados acima, estão representados na Tabela II. Não houve diferença estatisticamente significativa entre os grupos.

\section{4- DISCUSSÃO}

Diante do exposto, pode-se verificar um consumo elevado de suplementos pelos praticantes de atividade física, especialmente os suplementos protéico-energéticos, o que pode ser atribuído ao objetivo de ganho de massa muscular, observado na maioria dos entrevistados.

Os mesmos resultados foram verificados por outro estudo sobre o uso de suplementos em alunos de academias de ginástica de São Paulo, sendo cons- 
Tabela II: Valores médios e desvios-padrão do percentual de massa magra e gordura corporal dos diferentes grupos.

\begin{tabular}{lccc} 
& GC & GP & GPE \\
\hline & $\mathrm{N}=10$ & $\mathrm{~N}=10$ & $\mathrm{~N}=10$ \\
BIA $(\% \mathrm{MM})$ & $80,30 \pm 4,67$ & $82,40 \pm 5,70$ & $80,60 \pm 4,38$ \\
BIA (\%GORD) & $19,70 \pm 4,67$ & $17,60 \pm 5,70$ & $19,40 \pm 4,38$ \\
PREGAS $(\% G O R D)$ & $17,09 \pm 3,73$ & $15,58 \pm 5,58$ & $15,51 \pm 4,11$ \\
\hline
\end{tabular}

BIA = Bioimpedância, Pregas $=$ Somatório de Pregas

GC $=$ Grupo Controle, GP = Grupo Protéico e GPE = Grupo Protéico-Energético

tatado que os suplementos mais consumidos foram os aminoácidos ou outros concentrados protéicos ${ }^{11}$. Entretanto, Striegel et al. ${ }^{12}$, verificaram em seu estudo que $60,5 \%$ dos participantes utilizavam algum tipo de suplemento, sendo as vitaminas e os minerais os suplementos mais utilizados, seguidos pela proteína, carboidratos e creatina.

Em relação à orientação quanto ao uso de suplementos, observou-se que, o instrutor é o profissional mais procurado pelos alunos, seguido do nutricionista e amigos. O treinador parece, de fato, ser a principal fonte de informação sobre o uso de suplementos nestes ambientes ${ }^{11,13}$. Striegel et al. ${ }^{12}$ verificaram que, em relação à fonte de informação quanto ao consumo de suplementos, o médico foi citado como sendo a fonte preferida de informação, seguida da literatura pertinente, revistas especializadas e informação vinda de outros atletas ${ }^{12}$.

A grande procura pelos suplementos pode ser devido a um dos principais objetivos dos praticantes de musculação, o aumento de massa corporal magra, relatado por 73,5\% dos indivíduos. Neste sentido imagina-se uma associação entre ingestão de proteína e ganho de massa muscular, feita pelo usuário. Se admitirmos que o suprimento de proteínas pelos suplementos alcança quase a metade do recomendado para o dia, a soma da proteína da dieta habitual certamente superará a faixa de recomendação para indivíduos saudáveis, entre 0,8 e 1,0 g de proteínas/dia.

Quanto à composição corporal observou-se que o percentual de gordura corporal e o percentual de massa magra foram semelhantes entre os grupos, não havendo diferença estatística quanto ao uso do suplemento. Alguns estudos verificaram um aumento no percentual de massa magra após o uso de suplementos protéicos, no treinamento de resistência ${ }^{14,15}$. Ou- tro estudo verificou que a combinação de whey protein (proteína do soro do leite), juntamente com a caseína, promoveu um melhor aumento na massa corporal magra, depois de 10 semanas de um forte treinamento de resistência ${ }^{16}$.

Através do IMC foram verificadas taxas de sobrepeso e obesidade entre os indivíduos. No entanto a análise deste dado em praticantes de atividade física deve ser cautelosa pois em indivíduos com grandes quantidades de massa corporal magra os valores de gordura corporal podem ser superestimados ${ }^{17}$.

Deve-se ressaltar que estes dados devem ser analisados levando-se em conta o fato de que estes participantes são praticantes de atividade física e não atletas de competição e também são influenciados pelo tamanho amostral reduzido. Por outro lado destacase a importância de estudo neste tipo de indivíduo, visando um diagnóstico que permita uma orientação nutricional correta.

O presente estudo confirma os resultados previamente descritos na literatura em relação ao consumo de suplementos por parte dos praticantes de atividade física. $\mathrm{O}$ consumo deste tipo de produto sem uma orientação adequada leva a excessiva ingestão protéica e também energética, influenciando no aumento do percentual de gordura corporal. Por isso é necessário uma adequação alimentar energética e de nutrientes, antes da escolha ou uso desnecessário de um suplemento alimentar.

\section{5- AGRADECIMENTO}

À FAPESP pela bolsa de Mestrado (Gisele Sales Gomes) e pelas bolsas de Iniciação Científica (Gabriel Carvalho Degiovanni e Monike Ribeiro Garlipp), concedidas para realização deste estudo. 
Gomes GS, Degiovanni GC, Garlipp MR, Chiarello PG, Jordão Jr AA. Caracterization of nutritional supplements use by persons practicing physical exercise at gyms. Medicina (Ribeirão Preto) 2008; 41 (3): 327-31.

ABSTRACT: Introduction: There is an increasingly common search for nutritional supplements among gym clients, often without appropriate orientation. Objective: The objective of the present investigation was to determine the use of nutritional supplements by persons practicing physical exercise at gyms in Ribeirão Preto-SP and the impact of this in the body composition. Methods: A questionnaire was applied to 102 males aged 20 to 40 years at 10 gyms in Ribeirão Preto-SP. After responding to the questionnaire, 30 individuals were submitted to evaluation of body composition and classified into 3 groups of 10 subjects each: no consumption of supplements $(C G)$, exclusive consumption of protein supplements $(P G)$, and use of protein-energy supplements (PEG). Results: The results showed that $52 \%$ of the subjects consumed some type of supplement. Muscle building was practiced by $92 \%$ of the interviewees, with an increase in lean mass being the major objective reported. The amount of protein consumed by $P G$ and PEG subjects by ingesting the supplements represented, on average, $47 \%$ and $48 \%$, respectively, of the daily protein needs considering the recommendation of $1 \mathrm{~g}$ protein $/ \mathrm{kg}$ body weight. While the nutritionist is the professional most frequently associated with diets, the muscle building instructor is the professional most frequently consulted by the gym clients for the use of supplements. The evaluation of body composition revealed similar percent lean mass and percent body fat for the subjects who used supplements or not. Conclusion: The consumption of supplements by gym clients is elevated, often without appropriate specialized guidance, with no difference in body composition being observed when these products are consumed.

Key-words: Body Composition. Physical Activity. Diet. Exercise.

\section{REFERÊNCIAS}

1 - Diretriz da Sociedade Brasileira de Medicina do Esporte. Modificações dietéticas, reposição hídrica, suplementos alimentares e drogas: comprovação de ação ergogênica e potenciais riscos para a saúde. Rev. bras. med. esporte. 2003; 9 (2):4356.

2 - Rocha LP, Pereira MVI. Consumo de suplementos nutricionais por praticantes de exercícios físicos em academias. Rev. nutr. (Campinas) 1998;(11 supl 1):76-82.

3 - Viviani MT, Garcia Junior JR. Análise dos conhecimentos sobre nutrição básica e aplicada de profissionais de Educação Física e Nutrição. Rev. nutr. pauta 2003; (53):26-9.

4 - Kanayama G, Gruber AJ, Pope HGJ, Borowiecki JJ, Hudson Jl. Over-the-counter drug use in gymnasiums: an underrecognized substance abuse problem? Psychoter. psychosom. 2001; 70:137-40.

5 - Millman RB, Ross EJ. Steroid and nutritional supplement use in professional athletes. Am. j. addict. 2003;12:S48-S52.

6 - Geyer H, Parr MK, Reinhart U, Schrader Y, Mareck U, Schanzer W. Analysis of non-hormonal nutritional supplements for anabolic steroids-Results of na international study. Int. j. sports med. 2004; 25: 124-9.

7 - Iriart JAB, Andrade TM. Musculação, uso de esteróides anabolizantes e percepção de risco entre jovens fisiculturistas de um bairro popular de Salvador, Bahia, Brasil. Cad. saúde pública 2002;18(5):1379-87.

8 - Pamplona AP, Kazapi, IAM. Avaliação dietética de praticantes de atividade física em diferentes modalidades esportivas: um estudo comparativo. Rev. nutr. pauta 2004;(66):61-5.

9 - Rabito El, Vannucchi GB, Suen VVM, Neto LLC, Marchini JS. Estimativa de peso e altura de pacientes hospitalizados e imobilizados. Rev. nutr. (Campinas) 2006; 19(6): 655-61.
10 - Jordao AA, Bellucci AD, Oliveira JED, Marchini JS. Midarm computerized tomography fat, muscle and total areas correlation with nutritional assessment data. Int. j. obes. 2004; 28 (11): 1451-5.

11 - Pereira RF, Lajolo FM, Hirschbruch MD. Consumo de suplementos por alunos de academias de ginástica em São Paulo. Rev. nutr. (Campinas) 2003;16(3):265-72.

12 - Striegel H, Simon P, Wurster C, Niess AM, Ulrich R. The use of nutritional supplements among master athletes. Sports med. 2006;27:236-41.

13 - Sundgot-Borgen J, Berglund B, Torstveit MK. Nutritional supplements in Norwegian elite athletes- impact of international ranking and advisors. Scand j. med. sci. sports 2003;13:138-44.

14 - Candow DG, Burke NC, Smith-Palmer T, Burke DG. Effect of whey and soy protein supplementation combined with resistance training in young adults. Int. j. sport nutr. exerc. metab. 2006; 16 (3): 233-44.

15 - Cribb PJ, Hayes A. Effects of supplement timingl and resistance exercise on skeletal muscle hypertrophy. Med. sci. sports exerc. 2006;38(11):1918-25.

16 - Kerksick CM, Rasmussen CJ, Lancaster SL, Magu B, Smith $P$, Melton $C$, et al. The effects of protein and amino acid supplementation on performance and training adaptations during tem weeks of resistance training. J. strength. cond. res. 2006;20(3):643-53.

17 - Fernandes Filho J. A prática da avaliação física: testes, medidas e avaliação física em escolares, atletas e academias de ginástica. 2. ed. Rio de Janeiro: Shape, 2003.

Recebido para publicação em 25/01/2008

Aprovado para publicação em 15/07/2008. 